\title{
Evaluating compression or expansion of morbidity in Canada: trends in life expectancy and health-adjusted life expectancy from 1994 to 2010
}

\section{Colin Steensma, MSc (1,2); Lidia Loukine, MSc (1); Bernard C. K. Choi, PhD $(1,3,4)$}

This article has been peer reviewed.

\begin{abstract}
Introduction: The objective of this study was to investigate whether morbidity in Canada, at the national and provincial levels, is compressing or expanding by tracking trends in life expectancy (LE) and health-adjusted life expectancy (HALE) from 1994 to 2010. "Compression" refers to a decrease in the proportion of life spent in an unhealthy state over time. It happens when HALE increases faster than LE. "Expansion" refers to an increase in the proportion of life spent in an unhealthy state that happens when HALE is stable or increases more slowly than LE.

Methods: We estimated LE using mortality and population data from Statistics Canada. We took health-related quality of life (i.e. morbidity) data used to calculate HALE from the National Population Health Survey (1994-1999) and the Canadian Community Health Survey (2000-2010). We built abridged life tables for seven time intervals, covering the period 1994 to 2010 and corresponding to the year of each available survey cycle, for females and males, and for each of the 10 Canadian provinces. National and provincial trends were assessed at birth, and at ages 20 years and 65 years.
\end{abstract}

Results: We observed an overall average annual increase in HALE that was statistically significant in both Canadian females and males at each of the three ages assessed, with the exception of females at birth. At birth, HALE increased an average of $0.2 \%(p=.08)$ and $0.3 \%(p<.001)$ annually for females and males respectively over the 1994 to 2010 period. At the national level for all three age groups, we observed a statistically nonsignificant average annual increase in the proportion of life spent in an unhealthy state, with the exception of men at age 65 , who experienced a non-significant decrease. At the provincial level at birth, we observed a significant increase in proportion of life spent in an unhealthy state for Newfoundland and Labrador (NL) and Prince Edward Island (PEI).

Conclusion: Our study did not detect a clear overall trend in compression or expansion of morbidity from 1994 to 2010 at the national level in Canada. However, our results suggested an expansion of morbidity in NL and PEI. Our study indicates the importance of continued tracking of the secular trends of life expectancy and HALE in Canada in order to verify the presence of compression or expansion of morbidity. Further study should be undertaken to understand what is driving the observed expansion of morbidity in NL and in PEI.

Keywords: life expectancy, health expectancy, compression, expansion, mortality, morbidity, trend, health-related quality of life

\section{Highlights}

- Life expectancy (LE) and healthadjusted life expectancy (HALE) increased consistently from 1994 to 2010 for both Canadian females and males.

- HALE gains observed in the Canadian population over the reporting period were primarily associated with a decrease in mortality.

- The Canadian population appeared to be experiencing a period of relative stability in health expectancy from 1994 to 2010: no clear overall trend in compression or expansion of morbidity for the reporting period was detected in Canada.

\section{Introduction}

Two major potential scenarios have been proposed for future mortality and morbidity patterns. The "compression of morbidity" scenario anticipates an increase in life expectancy (LE) and a decrease in the proportion of life spent with serious disease and disability. ${ }^{1-3}$ This is possible when shifts in future disease patterns delay disease onsets to older ages. People will live longer (due to reduced mortality) with reduced morbidity.

The "expansion of morbidity" scenario anticipates an increase in the life expectancy and an increase in the proportion of life spent with underlying illness or disability. ${ }^{4-5}$ This is achieved when medical

\footnotetext{
Author references:

1. Public Health Agency of Canada, Government of Canada, Ottawa, Ontario, Canada

2. Department of Social and Preventive Medicine, Université de Montréal, Montréal, Quebec, Canada

3. Dalla Lana School of Public Health, University of Toronto, Toronto, Ontario, Canada

4. Injury Prevention Research Center, Shantou University Medical College, Shantou, China
}

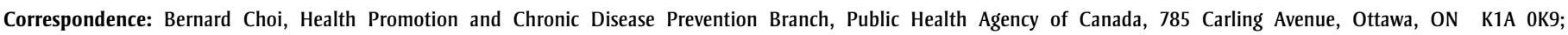
Tel: 613-797-3821; Fax: 613-941-2057; Email: bernard.choi@phac-aspc.gc.ca 
advances reduce mortality and case fatality but the disease patterns remain the same. Improved medical care increases survival and enables individuals to live despite illness. People will live longer (due to reduced mortality) but with increased morbidity and duration of morbidity. Determining which of these scenarios predominates will provide important information on the overall disease burden for health jurisdictions, with implications for strategic planning for future health care services and delivery.

Health expectancy, defined as life expectancy in a defined state of health, ${ }^{6,7}$ is an important tool for monitoring trends in population health and for evaluating the evidence for the compression or expansion of morbidity scenarios. A useful metric of health expectancy is "health-adjusted life expectancy" (HALE), defined as the average number of healthy years that a person would live under the mortality and morbidity prevailing at that time. ${ }^{8}$

Studies evaluating recent national trends in health expectancy within economically developed jurisdictions ${ }^{9-19}$ have shown evidence for both scenarios: some countries and autonomous regions appear to be experiencing an expansion of morbidity $^{9-12}$ while others indicate a compression of morbidity. ${ }^{13-16}$ One country demonstrated scenarios that differed by age group. ${ }^{17}$ In Canada, studies of health expectancy trends at the national level have given mixed results. One study reported a period of morbidity expansion from 1986 to 1991 followed by compression from 1991 to $1996,{ }^{18}$ while another comparing health expectancy in 1994 and 2007 suggested an overall expansion of morbidity between those two reporting periods. ${ }^{19}$

One of the challenges of assessing trends in health expectancy from available national surveys is the lack of consistent data over time. Many of the existing studies have evaluated trends using different disability measures across reporting periods ${ }^{12,15,16}$ and/or a limited number of reporting periods. ${ }^{11,16,17,19}$

Another challenge is that only a few evaluations of trends in health expectancy have been done at the sub-national level. ${ }^{20-22}$ At the provincial level in Canada, a study in Quebec ${ }^{22}$ found a larger proportion of life with disability in 1998 as compared to 1986, which suggests an expansion of morbidity during this period. In Canada, provincial estimates of health expectancy trends are a useful starting point for public health decision makers to plan resource allocation, since this is the jurisdictional level where health care is implemented.

The purpose of this study was to evaluate changes in health-adjusted life expectancy (HALE) in the Canadian population for the period 1994 to 2010 using multiple cycles of nationally representative surveys that have similar design and employ the same measure of functional health (Health Utilities Index). Specifically, we assessed trends in expansion or compression of morbidity by measuring changes in proportion of life spent in an unhealthy state. These trends were assessed at birth, at age 20 years and age 65 years, by sex and by province.

\section{Methods}

We used mortality and population data from Statistics Canada to estimate life expectancy for seven time intervals that covered the period 1994 to 2010 and which corresponded to the years in which the survey data required to calculate HALE were available (described later on in this section). For HALE, additional self-reported morbidity data came from the Health Utilities Index (HUI) component of the National Population Health Survey (NPHS) and the Canadian Community Health Survey (CCHS) conducted by Statistics Canada.

Both the NPHS and the CCHS were designed to collect information on the health of the Canadian population residing in households. During the first three cycles (1994/95, 1996/97 and 1998/99) the NPHS contained both cross-sectional and longitudinal components. Beginning in 2000, the cross-sectional component of NPHS was taken over by CCHS. For this reason, we used NPHS cross-sectional data for the period of 1994 to 1999 and CCHS data for the period of 2000 to 2010.

The first cycle of the NPHS data collection took place in 1994/95 and continued every second year thereafter. Its initial core sample was 17276 individuals living in Canada's 10 provinces. ${ }^{23}$ The household response rates for the cross-sectional component at the national level in the first three cycles were $88.7 \%, 82.6 \%$ and $89.7 \%$, respectively.

The CCHS includes a sample of about 130000 respondents and was designed to provide reliable estimates at the local health region level. ${ }^{24}$ For this study, we used cycles of CCHS data where the HUI was available for all Canadian provinces: 2000/01, 2003, 2005 and 2009/10. The household-level response rates in those cycles varied from $72.3 \%(2009 / 10)$ to $84.7 \%$ (2000/01). Data for the CCHS 2003 and 2005 were collected over a one-year period.

The target population of NPHS included respondents of all ages, but only those who were aged 12 years and over were targeted in the CCHS. As such, for the group under age 12 years, we substituted HUI values of 0.99 on the assumption that not all individuals in those age groups have perfect health. We chose the HUI value of 0.99 because the health-related quality of life is expected to be very high among children under age 12 years. Both surveys excluded persons living on Indian reserves and Crown lands, residents of health institutions, full-time members of the Canadian Forces living on Canadian Forces bases, and residents of some remote areas in Ontario and Quebec. Our analysis excluded the three Canadian territories, since data were not available in all of our selected cycles.

We used data from Statistics Canada ${ }^{25}$ to estimate mortality rates by province, sex and five-year age group. The three-year moving average method was used to obtain robust estimates, which is particularly important for calculating values for provinces with a small population. Three years of data are needed to provide large enough numbers to ensure that the mortality rates, which are used to estimate LE and HALE, are sufficiently robust. The three-year periods we used corresponded to the timing of the seven survey cycles used to calculate HALE: 1993 to 1995, 1995 to 1997,1997 to 1999,2000 to 2002 , 2002 to 2004, 2004 to 2006 and 2009 to 2011.

We measured health-related quality of life (HRQL) with the Health Utilities Index (HUI) Mark 3 instrument, which is available in both surveys. ${ }^{24,26}$ HUI is a multiattribute utility measure that defines health states according to eight attributes 
(vision, hearing, speech, ambulation, dexterity, emotion, cognition and pain), with five or six levels of functioning ranging from normal to severely limited functioning for each. The overall scores of the HUI range from -0.36 (the worst possible health state, e.g. a state in which death might be preferable) through 0.0 (death) to 1.0 (the best possible health state). Differences of 0.03 or more in overall HUI scores are considered to be clinically important. $^{26}$

We used the Chiang method, ${ }^{27}$ combined with the Hsieh method, ${ }^{28}$ to generate period life tables by sex using 19 standard age groups $(<1,1-4,5-9, \ldots 80-85$ and $85+$ years). The Chiang method is an established method widely used internationally to build abridged life tables. Agespecific mortality rates are used within the life table to calculate the probability of dying at each age interval, which are then applied to a hypothetical population cohort. The Hsieh method, based on the Gompertz function, was used to provide an accurate estimate of LE for the last open-ended $85+$ age interval. We applied the modified Sullivan method ${ }^{7}$ for the HALE calculation. According to this method, the "life-years lived" in each age interval was adjusted by the HUI. HALE variance was calculated following Mathers' method, ${ }^{9}$ which takes into account the variance of the probability of dying generated by the life-table method and the variance of the HUI.

To analyze the trend in health expectancy, and more specifically the morbidity scenarios, we calculated the annual percent rate of change in HALE and the "proportion of life spent in an unhealthy state," represented by (LE-HALE)/LE, by fitting a log-linear regression model. It is necessary to assess the difference between HALE and LE, proportional to LE since HALE is essentially a measure of LE weighted according to health-related quality of life and is thus highly correlated with LE.

As an additional measure of the contribution of HRQL to HALE trends in Canada, we decomposed the differences in HALE between the baseline reporting period (1994/95) and all subsequent periods into mortality and morbidity (HRQL) components using the Arriaga method ${ }^{29}$ adopted for the Sullivan method. ${ }^{30}$

\section{Results}

Mean HUI values fluctuated over the course of our study period for the Canadian population aged 12 years and older (Figure 1). Both females and males experienced a statistically significant average increase in the HUI value of just under 0.01 during the study period: from 0.862 in $1994 / 95$ to 0.871 in $2009 / 10$ for females $(p<.01)$ and from 0.879 in $1994 / 95$ to 0.886 in $2009 / 10$ for males $(p<.05$ ). However, while both females and males experienced a clinically important increase in HRQL from $1994 / 95$ to $1996 / 98$ (i.e. an increase in HUI of 0.03 or greater), the overall HRQL increase for the entire study period was not clinically important for either sex.

HALE increased consistently over the reporting period for both Canadian females and males (Tables 1A, 1B and 1C). For females, HALE increased by 3.3 years at birth, 3.1 years at age 20 and 2.0 years at age 65 . However, only females at age 20 and 65 years experienced significant annual average increases in HALE: $0.2 \%(p<.05)$ and $0.7 \%(p<.001)$ respectively. For males, HALE increases from $1994 / 95$ to $2009 / 10$ were 4.3 years at birth, 4.0 years at age 20 and 2.6 years at age 65 . This corresponds to significant annual average increases in HALE at each of these age groups: $0.3 \%$ at birth, $0.4 \%$ at age 20 and $1.2 \%$ at age 65 ( $p<.001$ for each).
The proportion of life spent in an unhealthy state [(LE-HALE)/LE] fluctuated over the course of our study period. For Canadian females and males at birth this proportion decreased from 1994/95 (females $14 \%$, males $12 \%$ ) to $1996 / 97$ (females $11 \%$, males $9 \%$ ), which indicated compression of morbidity. It then increased in the remaining period up to $2009 / 10$ (females $13 \%$, males $11 \%$ ) (Table 1A), which indicated expansion of morbidity. For the overall study period, the proportion of life spent in an unhealthy state did not significantly change (Tables $1 \mathrm{~A}, 1 \mathrm{~B}, 1 \mathrm{C}$ ), indicating neither compression nor expansion of morbidity. This same pattern was observed in females and males at age 20 and females at age 65 (Tables 1B, 1C). Males at age 65 experienced a non-significant decrease in annual average change of proportion of life spent in an unhealthy state.

Decomposition of the differences in HALE at birth for each reporting period compared to the baseline values of 1994/95 demonstrated a continual increase in HALE gains associated with the mortality component (Table 2). However, the gains attributed to HRQL (i.e. the morbidity component) fluctuated throughout the study period, also suggesting no clear trend in expansion or compression of morbidity. These trends were similar for both females and males.

HALE trends in the provinces largely mirrored those in the Canadian population as
FIGURE 1

Mean Health Utilities Index values, population aged 12 years and older, by sex and reporting period, Canada, 1994 to 2010

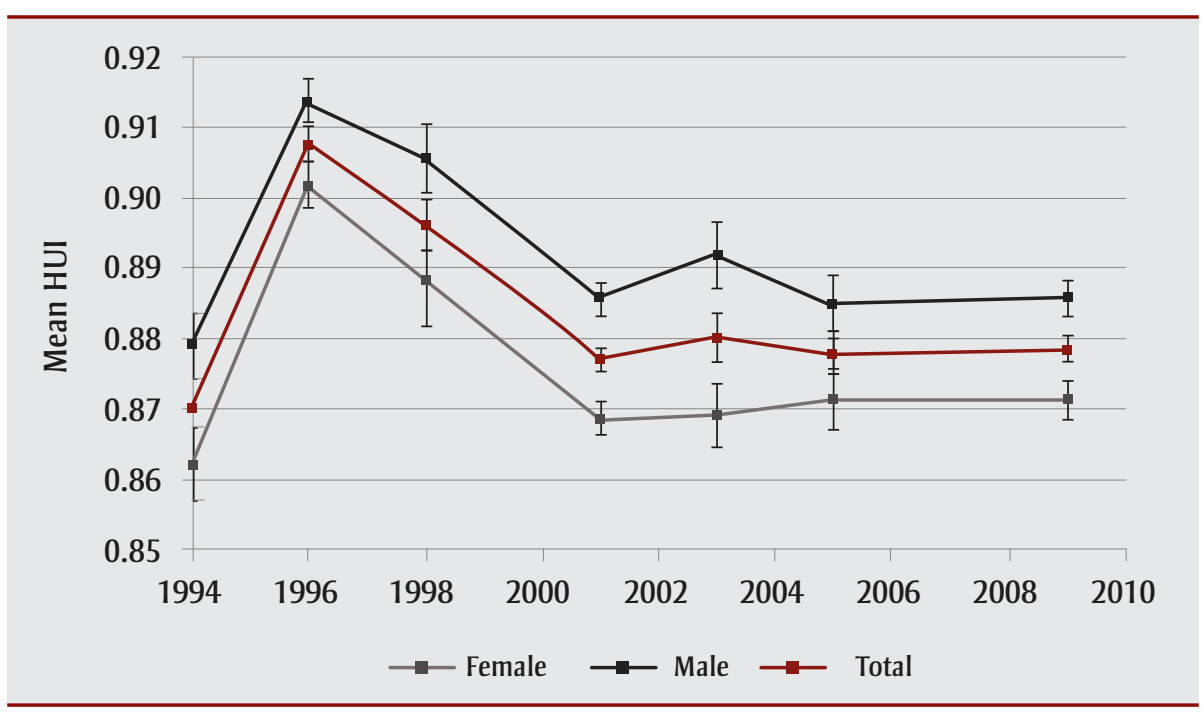

Abbreviation: HUI, Health Utilities Index. 
TABLE 1A

Life expectancy, health-adjusted life expectancy and proportion of life spent in an unhealthy state at birth, by sex and reporting period, Canada, 1994 to 2010

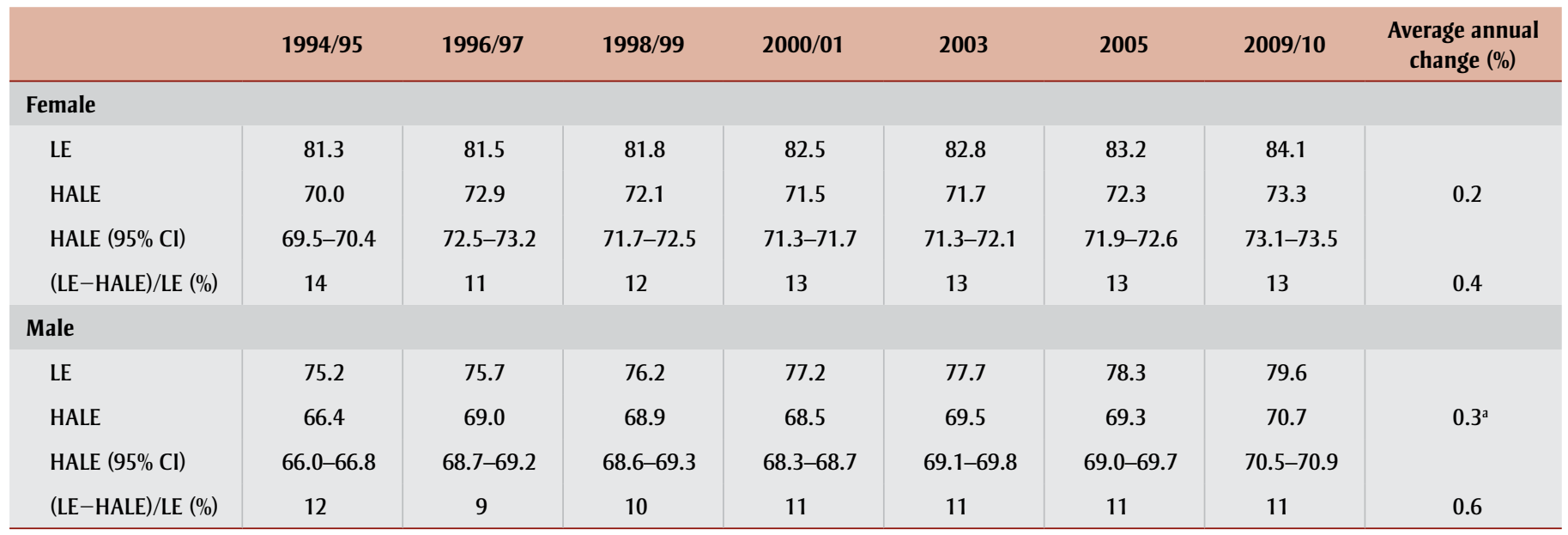

Abbreviations: $\mathrm{Cl}$, confidence interval; HALE, health-adjusted life expectancy; LE, life expectancy; (LE - HALE)/LE, the proportion of life spent in an unhealthy state. ${ }^{\mathrm{a}} p<.05$.

a whole (Tables 3A, 3B). However, there were provincial differences. From 1994/95 to $2009 / 10$, significant annual average increases in HALE at birth (both sexes combined) were observed in British Columbia and Quebec only. At age 65, HALE increased significantly in all provinces except NL and Nova Scotia.

In terms of proportion of life spent in an unhealthy state, at birth and at age 65, similar to the Canadian trend, most provinces did not experience significant changes over the study period. The exceptions were NL and PEI, each of which had a significant increase at birth, suggesting an expansion of morbidity. When results were stratified by sex (not shown), the significant increase in proportion of life spent in an unhealthy state at birth persisted only for males in NL and PEI. At age 65 , males in NL experienced a significant increase in the proportion, while Manitoban males exhibited a significant decrease.

\section{Discussion}

Our study provides a comprehensive look into the public health scenarios of compression or expansion of morbidity in Canada by tracking trends in life expectancy and health-adjusted life expectancy from 1994 to 2010. Our results demonstrate that both LE and HALE increased for females and males during the study period. While the proportion of life spent in an unhealthy state fluctuated, the

TABLE 1B

Life expectancy, health-adjusted life expectancy and proportion of life spent in an unhealthy state at age 20, by sex and reporting period, Canada, 1994 to 2010

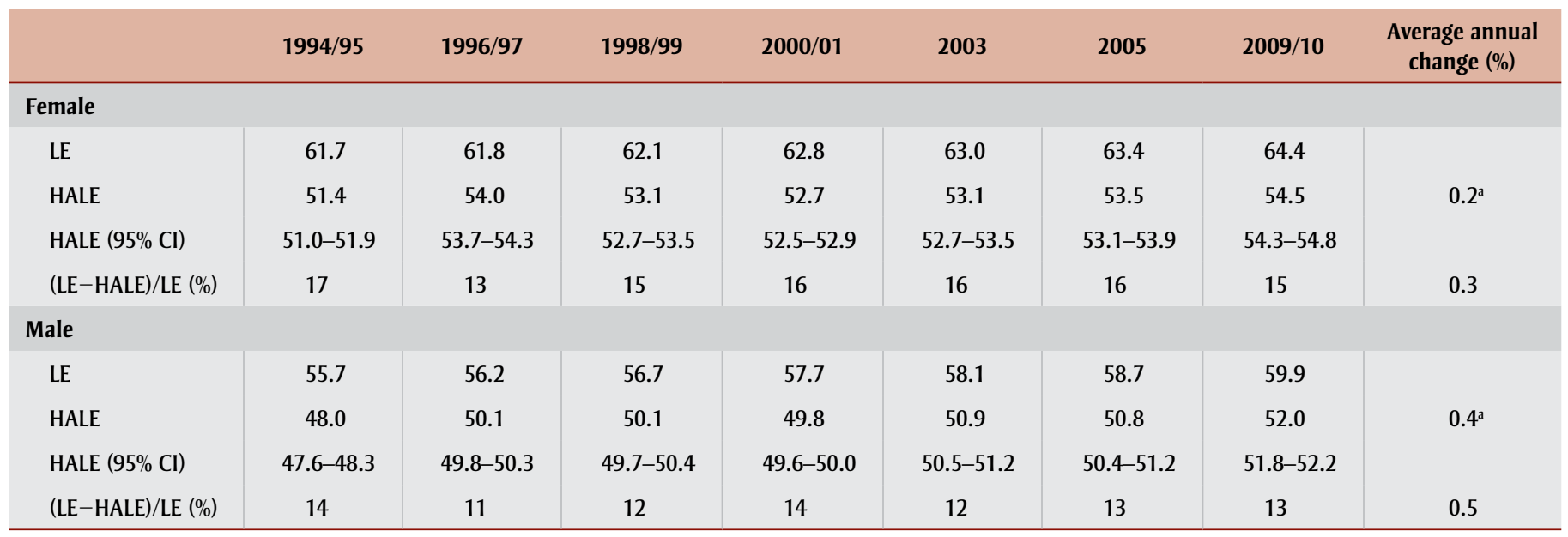

Abbreviations: $\mathrm{CI}$, confidence interval; HALE, health-adjusted life expectancy; LE, life expectancy; (LE - HALE)/LE, the proportion of life spent in an unhealthy state. ${ }^{\mathrm{a}} \mathrm{p}<.05$. 
TABLE 1C

Life expectancy, health-adjusted life expectancy and proportion of life spent in an unhealthy state at age 65, by sex and reporting period, Canada, 1994 to 2010

\begin{tabular}{|c|c|c|c|c|c|c|c|c|}
\hline & 1994/95 & 1996/97 & 1998/99 & $2000 / 01$ & 2003 & 2005 & 2009/10 & $\begin{array}{c}\text { Average annual } \\
\text { change }(\%)\end{array}$ \\
\hline \multicolumn{9}{|l|}{ Female } \\
\hline $\mathrm{LE}$ & 19.9 & 19.9 & 20.2 & 20.7 & 20.9 & 21.3 & 22.1 & \\
\hline HALE & 14.8 & 15.6 & 15.3 & 15.4 & 15.7 & 16.0 & 16.8 & $0.7^{\mathrm{a}}$ \\
\hline HALE $(95 \% \mathrm{Cl})$ & $14.4-15.1$ & $15.3-15.9$ & $15.0-15.7$ & $15.2-15.6$ & $15.4-16.1$ & $15.6-16.3$ & $16.7-17.0$ & \\
\hline (LE-HALE)/LE (\%) & 26 & 22 & 24 & 26 & 25 & 25 & 24 & 0.05 \\
\hline \multicolumn{9}{|l|}{ Male } \\
\hline LE & 15.8 & 15.9 & 16.2 & 17.0 & 17.4 & 17.9 & 18.9 & \\
\hline HALE & 12.3 & 12.8 & 12.8 & 13.1 & 14.0 & 14.2 & 14.9 & $1.2^{\mathrm{a}}$ \\
\hline HALE $(95 \% \mathrm{Cl})$ & $12.0-12.6$ & $12.6-13.1$ & $12.5-13.1$ & $13.0-13.3$ & $13.7-14.3$ & $13.9-14.5$ & $14.7-15.1$ & \\
\hline$(\mathrm{LE}-\mathrm{HALE}) / \mathrm{LE}(\%)$ & 22 & 19 & 21 & 23 & 19 & 21 & 21 & -0.1 \\
\hline
\end{tabular}

Abbreviations: $\mathrm{Cl}$, confidence interval; HALE, health-adjusted life expectancy; LE, life expectancy; (LE - HALE)/LE, the proportion of life spent in an unhealthy state. ${ }^{\mathrm{a}} p<.05$.

statistically non-significant average annual increase in this proportion observed over the entire study period appeared to indicate that there was no clear overall trend in compression or expansion of morbidity from 1994 to 2010 in Canada. This lack of a clear trend can also be seen in the decomposition of HALE differences, which did not show any consistent trends in gains or losses associated with the morbidity component (HRQL).

The trend results for the provinces indicate that, while health expectancy values generally reflect a certain amount of stability between 1994/95 and 2009/10, there may be some expansion of morbidity occurring among males in NL and PEI. Removing data for 1996/97, where a clinically important increase in HUI was observed, did not change the results. Further study is needed to assess which determinants of health may be influencing the changes observed in NL and PEI.

A previous study of morbidity trends in the Canadian adult population found that disability-free life expectancy as a proportion of life expectancy had decreased, suggesting an expansion of morbidity between 1994/95 and 2007. ${ }^{19}$ However, that study only used two reporting periods and as such does not allow meaningful interpretation of annual changes occurring within this period. Our findings are similar to a study of disability trends in OECD countries, ${ }^{31}$ which found that disability prevalence, as measured by limitations in activities of daily living, remained stable in the Canadian population aged 65 years and older for the period of 1996 to 2003. With respect to the provincial results, the

TABLE 2

Contribution of mortality and morbidity components to differences in HALE at birth for each reporting period (compared to baseline period), by sex, Canada, 1994 to 2010

\begin{tabular}{|c|c|c|c|c|c|c|c|}
\hline Gains $^{\mathbf{b}}$ & 1994/95 & 1996/97 & 1998/99 & 2000/01 & 2003 & 2005 & $2009 / 10$ \\
\hline \multicolumn{8}{|l|}{ Female } \\
\hline Mortality gain component & 0 (REF) & 0.1 & 0.4 & 0.8 & 1.0 & 1.3 & 2.0 \\
\hline Morbidity (HRQL) gain component & 0 (REF) & 2.7 & 1.7 & 0.7 & 0.7 & 0.9 & 1.3 \\
\hline Mortality gain component & 0 (REF) & 0.4 & 0.8 & 1.6 & 2.0 & 2.4 & 3.4 \\
\hline Morbidity (HRQL) gain component & 0 (REF) & 2.1 & 1.7 & 0.5 & 1.1 & 0.6 & 0.9 \\
\hline
\end{tabular}

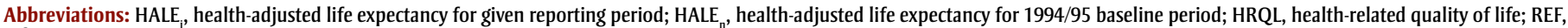
reference group.

a The sum of mortality and morbidity gain components may not exactly match the HALE gain due to rounding.

${ }^{\mathrm{b}}$ Gains in this table are expressed in years. 
TABLE 3A

Average annual change in health-adjusted life expectancy and in proportion of life spent in an unhealthy state at birth, both sexes combined, by province, Canada, 1994 to 2010

\begin{tabular}{|c|c|c|c|c|c|c|c|c|}
\hline & 1994/95 & 1996/97 & 1998/99 & $2000 / 01$ & 2003 & 2005 & $2009 / 10$ & $\begin{array}{l}\text { Average annual } \\
\text { change (\%) }\end{array}$ \\
\hline \multicolumn{9}{|l|}{ Alberta } \\
\hline HALE & 68.3 & 70.8 & 70.7 & 69.1 & 70.3 & 70.3 & 71.3 & +0.1 \\
\hline$(\mathrm{LE}-\mathrm{HALE}) / \mathrm{LE}(\%)$ & 13 & 10 & 11 & 14 & 13 & 13 & 13 & +0.7 \\
\hline \multicolumn{9}{|l|}{ British Columbia } \\
\hline \multicolumn{9}{|l|}{ Manitoba } \\
\hline HALE & 68.0 & 70.4 & 68.8 & 69.3 & 69.7 & 70.2 & 70.0 & +0.1 \\
\hline$(\mathrm{LE}-\mathrm{HALE}) / \mathrm{LE}(\%)$ & 13 & 10 & 12 & 12 & 12 & 12 & 13 & +0.4 \\
\hline \multicolumn{9}{|l|}{ New Brunswick } \\
\hline \multicolumn{9}{|c|}{ Newfoundland and Labrador } \\
\hline HALE & 68.5 & 71.0 & 71.5 & 69.1 & 68.5 & 68.2 & 69.2 & -0.1 \\
\hline$(\mathrm{LE}-\mathrm{HALE}) / \mathrm{LE}(\%)$ & 11 & 8 & 8 & 11 & 12 & 13 & 13 & $+2.5^{\mathrm{a}}$ \\
\hline \multicolumn{9}{|l|}{ Nova Scotia } \\
\hline HALE & 65.8 & 68.9 & 69.3 & 68.2 & 68.9 & 68.5 & 69.2 & +0.2 \\
\hline$(\mathrm{LE}-\mathrm{HALE}) / \mathrm{LE}(\%)$ & 15 & 11 & 12 & 14 & 13 & 14 & 14 & +0.3 \\
\hline \multicolumn{9}{|l|}{ Ontario } \\
\hline HALE & 67.7 & 71.4 & 70.7 & 69.5 & 70.4 & 71.0 & 71.7 & +0.2 \\
\hline$(\mathrm{LE}-\mathrm{HALE}) / \mathrm{LE}(\%)$ & 14 & 10 & 11 & 13 & 13 & 12 & 13 & +0.7 \\
\hline$(\mathrm{LE}-\mathrm{HALE}) / \mathrm{LE}(\%)$ & 11 & 9 & 10 & 10 & 10 & 11 & 10 & +0.4 \\
\hline \multicolumn{9}{|l|}{ Saskatchewan } \\
\hline HALE & 68.7 & 70.3 & 70.8 & 69.3 & 70.5 & 69.7 & 70.1 & +0.0 \\
\hline$(\mathrm{LE}-\mathrm{HALE}) / \mathrm{LE}(\%)$ & 13 & 11 & 10 & 13 & 11 & 13 & 12 & +0.4 \\
\hline
\end{tabular}

Abbreviations: HALE, health-adjusted life expectancy; (LE - HALE)/LE, the proportion of life spent in an unhealthy state.

${ }^{\mathrm{a}} p<.05$.

study from Quebec ${ }^{22}$ covered a period (1986-1998) most of which occurred before our study (1994-2010), so comparisons are difficult. That study suggested an expansion of morbidity, although once again, the use of only two reporting periods prevents meaningful interpretation of trends.

Our findings provide some support to the hypothesis of Robine and Michel, ${ }^{32}$ who predicted that economically developed countries would experience a pattern of initial expansion of morbidity due to increased survival rates with disabling conditions, followed by compression as improvements were made in controlling chronic diseases and improving health behaviours in new cohorts of older people. It is possible that Canada has progressed from the initial expansion of morbidity phase in the 1980 s and 1990 s into a period of stasis due to improvements in chronic disease prevention and health promotion. An assessment of healthy life expectancy trends in Canada during this earlier period ${ }^{33}$ suggests that there was a period of expansion of morbidity between 1986 and 1991. However, these trends will need to be followed over time to confirm this hypothesis. Robine and Michel also hypothesize a final stage in this "disability transition," in which 
TABLE 3B

Average annual change in health-adjusted life expectancy and in proportion of life spent in an unhealthy state at age 65 , both sexes combined, by province, Canada, 1994 to 2010

\begin{tabular}{|c|c|c|c|c|c|c|c|c|}
\hline & 1994/95 & 1996/97 & 1998/99 & $2000 / 01$ & 2003 & 2005 & $2009 / 10$ & $\begin{array}{c}\text { Average annual } \\
\text { change (\%) }\end{array}$ \\
\hline \multicolumn{9}{|l|}{ Alberta } \\
\hline HALE & 13.5 & 14.5 & 14.3 & 14.1 & 15.4 & 14.8 & 15.7 & $+0.8^{\mathrm{a}}$ \\
\hline$(\mathrm{LE}-\mathrm{HALE}) / \mathrm{LE}(\%)$ & 26 & 22 & 24 & 27 & 21 & 26 & 24 & -0.1 \\
\hline \multicolumn{9}{|l|}{ British Columbia } \\
\hline \multicolumn{9}{|l|}{ Manitoba } \\
\hline HALE & 12.9 & 14.3 & 13.8 & 14.2 & 14.2 & 15.2 & 15.3 & $+0.9^{\mathrm{a}}$ \\
\hline$(\mathrm{LE}-\mathrm{HALE}) / \mathrm{LE}(\%)$ & 29 & 21 & 24 & 25 & 25 & 21 & 23 & -0.9 \\
\hline \multicolumn{9}{|l|}{ New Brunswick } \\
\hline HALE & 13.2 & 13.8 & 13.6 & 13.1 & 13.7 & 13.2 & 14.4 & +0.3 \\
\hline (LE-HALE)/LE (\%) & 21 & 17 & 18 & 24 & 21 & 24 & 22 & +1.2 \\
\hline \multicolumn{9}{|l|}{ Nova Scotia } \\
\hline HALE & 13.0 & 14.2 & 13.9 & 13.4 & 13.7 & 14.1 & 14.4 & +0.4 \\
\hline (LE-HALE)/LE (\%) & 25 & 19 & 22 & 26 & 25 & 24 & 25 & +1.0 \\
\hline \multicolumn{9}{|l|}{ Ontario } \\
\hline HALE & 13.3 & 14.4 & 14.2 & 14.0 & 14.7 & 15.4 & 15.8 & $+0.9^{\mathrm{a}}$ \\
\hline (LE-HALE)/LE (\%) & 26 & 20 & 22 & 26 & 24 & 22 & 24 & +0.1 \\
\hline \multicolumn{9}{|l|}{ Prince Edward Island } \\
\hline (LE-HALE)/LE (\%) & 22 & 20 & 22 & 20 & 20 & 22 & 19 & -0.5 \\
\hline \multicolumn{9}{|l|}{ Saskatchewan } \\
\hline HALE & 14.4 & 14.4 & 14.6 & 14.4 & 15.2 & 14.9 & 15.4 & $+0.4^{\mathrm{a}}$ \\
\hline$($ LE-HALE)/LE (\%) & 24 & 23 & 22 & 25 & 22 & 24 & 23 & -0.2 \\
\hline
\end{tabular}

Abbreviations: HALE, health-adjusted life expectancy; (LE - HALE)/LE, the proportion of life spent in an unhealthy state.

${ }^{\mathrm{a}} p<.05$.

morbidity expands again due to the emergence of very old and frail populations. ${ }^{32}$ This would also need to be monitored on an ongoing basis in the Canadian population.

\section{Strengths and limitations}

The main strength of our study was the ability to detect changes in healthy life expectancy at the population level over a reasonably long period of time with multiple reporting points. Our study used seven reporting secular time points representing 15 years of observation taken from two major national health studies that used virtually the same sampling frame of the Canadian household population and the same measure of health-related quality of life. The combination of length of reporting period and frequency of reporting points in our study exceeded that of all other studies we identified in the literature.

Our study had several limitations. It was beyond the scope of our study to assess the impact of socioeconomic and behavioural factors on healthy life expectancy trends. For instance, it is possible that provinces may experience a decline in healthy life expectancy due to loss of healthy adults migrating to other provinces 
for work. ${ }^{34}$ Further studies are needed to test this hypothesis, as well as other potential socioeconomic factors. Unlike most studies assessing trends in health expectancy, we did not use a measure of limitations in activities of daily living. This limits our ability to make comparisons to results from studies conducted for other nations. However, a validation study of several measures of disability ${ }^{35}$ found the HUI to correlate well with a measure of activity and participation limitations, suggesting that trends measured with HUI should reflect those found using these other measures.

It should also be noted that it was beyond the scope of our study to assess a third proposed morbidity scenario called "dynamic equilibrium." ${ }^{36}$ This scenario hypothesizes a state of equilibrium where life expectancy increases, while a longer proportion of life spent living with chronic diseases is counteracted by a decrease in the severity of these diseases. Future studies of Canadian morbidity trends should incorporate more explicit measures of severity of disability in order to assess whether the Canadian population is experiencing this scenario.

With respect to the data sources used in our study, neither the NPHS nor the CCHS cover the Canadian population living in institutions, including those associated with long-term care. Additionally, the CCHS only covers the population aged 12 years and older, which obliged us to use assumed HUI values for the population under age 12 years. It is thus possible that the health expectancy values for these excluded populations are different from those of the household population. There is a theoretical possibility of this affecting the direction of the trends over the reporting period, since there is a trend towards facilitating the elderly population to remain at home, which may contribute to greater proportions of incapacitated individuals remaining in the general population.

Finally, the second (1996/97) and third $(1998 / 99)$ cycles of the NPHS are constituted of both a cross-sectional sample of the Canadian household population and panel members of the longitudinal cohort portion of this same study. As such, there is a possibility that health expectancy results from these two cycles differ from the other purely cross-sectional survey cycles. This is because surviving panel members might have contributed to a "healthy volunteer" effect whereby their ability to survive to, and ability to participate in, the subsequent rounds of followup were due to the fact that they were healthier than the general population. ${ }^{37}$ Indeed, we observed elevated average HUI values for these two cycles. We conducted a sensitivity analysis by removing the 1996/97 cycle data from our calculations: these results confirmed the statistically significant expansion of morbidity at birth for males living in NL and PEI, and relative stability for the total Canadian population.

\section{Conclusion}

Our study analyzed the trends in morbidity as compared to the trends in life expectancy at birth, at age 20 years and at age 65 years. In the context of population aging, it is important to monitor these two trends, because expansions and compressions of morbidity have very different impacts on future trends in health care expenditures. The lack of comparable data has been an issue in the past; this study provides valuable information to identify the direction Canada has taken over a 15 -year period. Additional results by province provide information that has been lacking up to now.

Contrary to other industrialized countries where compression or expansion of morbidity has been observed in studies for the last 30 to 40 years, the Canadian population as a whole appeared to be experiencing a period of relative stability in health expectancy from 1994 to 2010. However, there appeared to be an expansion of morbidity in NL and in PEI, particularly among males. Continued surveillance of health expectancy trends will be necessary to detect whether Canada makes further transitions towards increasing morbidity. Further study should also be undertaken to confirm these observations and to better understand what is driving the expansion of morbidity in NL and in PEI.

\section{Acknowledgements}

We are thankful to Dr. Heather Orpana, Health Promotion and Chronic Disease Prevention Branch, Public Health Agency of Canada, for providing helpful advice for the analysis and methods used in the study.

\section{Data sharing statement}

Data used in this study were accessed through sharing agreements with Statistics Canada and the Canadian provinces and territories. Other researchers can access Statistics Canada data through the Data Liberation Initiative of Statistics Canada.

\section{Conflicts of interest}

No funding was provided for this study. The authors have no competing interests to declare.

\section{Authors' contributions}

Colin Steensma contributed to the study design, interpretation of the data, drafting of the article and critical review of the article. Lidia Loukine contributed to the study design, statistical analyses, drafting of the article and critical review of the article. Bernard Choi contributed to the study concept and design, drafting of the article and critical review of the article.

\section{References}

1. Fries JF. Aging, natural death, and the compression of morbidity. Bull World Health Organ. 2002;80(3):245-50.

2. Fries JF. Measuring and monitoring success in compressing morbidity. Ann Intern Med. 2003;139(5 Part 2):455-9.

3. Fries J, Green L, Levine S. Health promotion and the compression of morbidity. The Lancet 1989;333(8636): 481-3.

4. Gruenberg EM. The failures of success. Milbank Memorial Fund Q/Health Soc. $1977 ; 55(1): 3-24$.

5. Kramer $M$. The rising pandemic of mental disorders and associated chronic diseases and disabilities. Acta Psychiatr Scand. 1980;62(S285):382-97.

6. Sanders BS. Measuring community health levels. Am J Public Health Nations Health. 1964;54(7):1063-70.

7. Sullivan DF. A single index of mortality and morbidity. HSMHA Health Rep. $1971 ; 86(4): 347-54$. 
8. Public Health Agency of Canada Steering Committee on Health-Adjusted Life Expectancy. Health-adjusted life expectancy in Canada: 2012 report by the Public Health Agency of Canada. Ottawa (ON): Public Health Agency of Canada; 2012 [Catalogue No.: HP35-32/2012E].

9. Mathers C. Trends in health expectancies in Australia 1981-1993. J Australian Popul Assoc. 1996;13(1):1-15.

10. Hashimoto S, Kawado M, Seko R, et al. Trends in disability-free life expectancy in Japan, 1995-2004. J Epidemiol. 2010;20(4):308-12.

11. Graham P, Blakely T, Davis P, Sporle A, Pearce N. Compression, expansion, or dynamic equilibrium? The evolution of health expectancy in New Zealand. J Epidemiol Community Health. 2004;58(8):659-66.

12. Cheung KSL, Yip PSF. Trends in healthy life expectancy in Hong Kong SAR 1996-2008. Eur J Ageing. 2010; 7(4):257-69.

13. Doblhammer G, Kytir J. Compression or expansion of morbidity? Trends in healthy-life expectancy in the elderly Austrian population between 1978 and 1998. Soc Sci Med. 2001;52(3): 385-91.

14. Bronnum-Hansen H. Health expectancy in Denmark, 1987-2000. Eur J Public Health. 2005;15(1):20-5.

15. Stewart ST, Cutler DM, Rosen AB. US trends in quality-adjusted life expectancy from 1987 to 2008: combining national surveys to more broadly track the health of the nation. Am J Public Health. 2013;103(11):e78-e87.

16. Sagardui-Villamor J, Guallar-Castillón P, Garcia-Ferruelo M, Banegas JR, Rodriguez-Artalejo F. Trends in disability and disability-free life expectancy among elderly people in Spain: 1986-1999. J Gerontol A Biol Sci Med Sci. 2005;60(8):1028-34.

17. Cambois E, Clavel A, Romieu I, Robine J. Trends in disability-free life expectancy at age 65 in France: consistent and diverging patterns according to the underlying disability measure. Eur J Ageing. 2008;5(4): 287-98.
18. Martel L, Bélanger A. An analysis of the change in dependence-free life expectancy in Canada between 1986 and 1996. In: Bélanger A, Gilbert S, eds. Report on the demographic situation in Canada 1998-1999. Ottawa (ON): Statistics Canada [Catalogue No.: 91-209-XIE].1999;164-186.

19. Mandich S, Margolis R. Changes in disability-free life expectancy in Canada between 1994 and 2007. Can Studies Popul. 2014;41(1-2):192-208.

20. Jia H, Zack MM, Thompson WW. State quality-adjusted life expectancy for US adults from 1993 to 2008. Qual Life Res. 2011;20(6):853-63.

21. Pinheiro P, Krämer A. Calculation of health expectancies with administrative data for North Rhine-Westphalia, a Federal State of Germany, 19992005. Popul Health Metr. 2009;19(7):4.

22. Pampalon $R$, Choinière $M$, Rochon $M$. L’espérance de santé au Québec. In: Camirand J, Aubin J, Audet N, et al., eds. Enquête québécoise sur les limitations d'activités 1998. Québec : Institut de la statistique du Québec. 2001; 399-420.

23. Tambay J, Catlin G. Sample design of the National Population Health Survey. Health Rep. 1995;7(1):29-38.

24. Béland Y. Canadian Community Health Survey - methodological overview. Health Rep. 2002;13(3):9-14.

25. Statistics Canada. CANSIM database: Table 051-0001: Estimates of population, by age group and sex for July 1 , Canada, provinces and territories, annual (persons unless otherwise noted) [Internet]. Ottawa (ON): Statistics Canada; [modified 2016 Sep 28; cited 2015 Jun 30]. Available from: http://www5.statcan.gc.ca/cansim /a26?lang = eng\&retrLang $=$ eng\&id $=0510001 \&$ paSer $=$ \&pattern $=\&$ stByVal $=1 \& \mathrm{p} 1=1 \& \mathrm{p} 2=37 \& \mathrm{tab}$ Mode $=$ dataTable $\&$ csid $=$

26. Feeny D, Furlong W, Torrance GW, et al. Multiattribute and single-attribute utility functions for the Health Utilities Index Mark 3 system. Med Care. 2002; 40(2):113-28.
27. Chiang CL. The life table and its applications. Malabar (FL): Robert E. Krieger Publishing; 1984.

28. Hsieh JJ. A general theory of life table construction and a precise abridged life table method. Biom J. 1991;33(2): 143-62.

29. Arriaga EE. Measuring and explaining the change in life expectancies. Demography. 1984;21(1):83-96.

30. Nusselder WJ, Looman CW. Decomposition of differences in health expectancy by cause. Demography. 2004;41(2):315-34.

31. Lafortune G, Balestat G. Trends in severe disability among elderly people: assessing the evidence in 12 OECD countries and the future implications. OECD Health Working Papers, No. 26. Paris: OECD Publishing; 2007. 81 p.

32. Robine JM, Michel JP. Looking forward to a general theory on population aging. J Gerontol A Biol Sci Med Sci. 2004;59(6):M590-7.

33. Chen J, Wilkins R, Ng E. Health expectancy by immigrant status, 1986 and 1991. Health Rep. 1996;8(3):29-38.

34. Norman P, Boyle P, Rees P. Selective migration, health and deprivation: a longitudinal analysis. Soc Sci Med. 2005;60(12):2755-71

35. Altman BM, Ng E, Berthelot JM. A comparative analysis of four disability/functional limitation modules in the 2003 Joint Canada/United States Survey of Health. In: Proceedings of the 2004 Joint Statistical Meetings of the American Statistical Association. Alexandria (VA): American Statistical Association; 2004:3256-63.

36. Manton K, Gu X, Lowrimore GR. Cohort changes in active life expectancy in the U.S. elderly population: experience from the 1982-2004 National Long-Term Care Survey. J Gerontol B Psychol Sci Soc Sci. 2008;63(5):S269S281.

37. Delgado-Rodriguez M, Llorca J. Bias. J Epidemiol Community Health. 2004; 58(8):635-41. 